\title{
Health Sciences Libraries Forecasting Information Service Trends for Researchers: Models Applicable to All Academic Libraries
}

\author{
Timothy J. Cain, Fern M. Cheek, Jeremy Kupsco, \\ Lynda J. Hartel, and Anna Getselman
}

To better understand the value of current information services and to forecast the evolving information and data management needs of researchers, a study was conducted at two research-intensive universities. The methodology and planning framework applied by health science librarians at Emory University and The Ohio State University focused on identifying the need for new or retooled information services supporting health and biomedical researchers and their increasing use of digital resources. The lessons learned and outcomes described herein are informing the development and implementation of new information service models and can help forecast changing user needs across the broader library community.

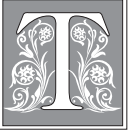

he unprecedented increase of information resources, methodologies, and products of modern academic research has prompted the library community to explore and create a growing array of offerings to support optimal information management. Parallel to these developments, academic units such as information technology, academic computing, and a wide variety of informatics and research departments have been delivering related and times overlapping services. This complex and fragmented service environment can be challenging, making it difficult for researchers to realize all the benefits of what is being offered. It can also create a formidable barrier between service receivers and providers. These developments have been prompting academic research libraries to reassess their information and data management services and solutions. While librarians have a general awareness of researcher needs, the work of the profession has focused on the more traditional

Timothy J. Cain, PhD, is Associate Professor of Biomedical Sciences at Ohio University; e-mail: caint@ohio.edu. Fern M. Cheek, AMLS, AHIP, is Associate Professor and Research Librarian at the Health Sciences Library, The Ohio State University; e-mail: cheek.27@osu.edu. Jeremy Kupsco, PhD, is Research Informationist at the Woodruff Health Sciences Center Library, Emory University; e-mail: jkupsco@emory.edu. Lynda J. Hartel, MLS, AHIP, is Associate Professor and Associate Director for Knowledge Integration at the Health Sciences Library, The Ohio State University; e-mail: lynda.hartel@osumc.edu. Anna Getselman, MLS, is Executive Director of the Augustus C. Long Health Sciences Library, Columbia University Medical Center; e-mail: ag3353@cumc.columbia.edu. (c) 2016 Timothy J. Cain, Fern M. Cheek, Jeremy Kupsco, Lynda J. Hartel, and Anna Getselman, Attribution-NonCommercial (http://creativecommons.org/licenses/by-nc/3.0/) CC BY-NC. 
outcomes of academic research (that is to say, literature reviews, cataloging published works, collection development, citation analysis, and the like). Today, librarians are actively engaged in all stages of the research life cycle and are observing firsthand how researchers struggle to manage their various information needs.

To meet the ever-evolving demands of the profession, contemporary authors have challenged the library community to reexamine the needed skills and professional development of staff members, evaluate the need for new library services and delivery models, and explore new organizational models and operational synergies. ${ }^{1}$

Investigating researchers' information needs at two research-intensive universities differing in key institutional attributes (in this case, public vs. private, large vs. medium) provided the authors with an opportunity to apply a common strategic planning framework with the targeted goal of assessing, implementing, and evaluating the information and support services in question.

While nearly all academic disciplines have been affected, the changes that digital innovations have driven in the health and biomedical sciences is unprecedented. As Bienenstock notes, "the government has made academic biomedical research a national priority since World War II," as evidenced in recent years by increased budget allocations to the National Institutes of Health (NIH) and its investment in biomedical research. ${ }^{2}$ Over the years, health sciences libraries have responded by moving the needs of researchers to the forefront of their organizational priorities.

Whether analyzing vast amounts of genomic data in search of DNA mutations, managing healthcare delivery through the use of integrated health information systems, or using medical imaging data to engineer customized surgical interventions and devices, the demand for information services presses even the most resourceful organizations. The demands for increasingly sophisticated information services and pressures to enhance information access at the point of care are challenging academic health sciences libraries to provide relevant and responsive services. These unique environmental pressures have driven many health sciences libraries to create and operationalize new service models, many of which are later adopted by the broader library community. Health sciences librarians have been early adopters of embedded librarian roles, have played increasingly more integral roles in large research grants such as the NIH Clinical and Translational Science Awards, and have been active partners in shepherding institutional and investigator efforts to meet federal funding compliance requirements. ${ }^{3}$

While this study has focused primarily on exploring current and future needs of researchers across the health professions, it can be reasonably argued that the lessons learned from exploring the health sciences community can help to inform user trends that promise to follow across all academic libraries.

The Woodruff Health Sciences Center Library at Emory University (HSL@Emory) serves a broad community of academic researchers, educators, and trainees spread across a wide range of institutional organizations and disciplines (that is, biological/ biomedical sciences, medicine, nursing, and public health). HSL@Emory also manages the health information resources and services provided to the clinical enterprise of Emory Healthcare and its five component institutions. The Emory Library system was aligned with the university's central information technology services in 2013, forming Library and Information Technology Services, LITS. Located in Atlanta, Georgia, Emory University is a medium-sized four-year, private research university that enrolls more than 14,000 students across all levels of training and employs nearly 28,000 faculty and staff across the University and Emory Healthcare. Emory University is supported by more than \$521 million in external funding in 2014.

The Health Sciences Library at The Ohio State University (HSL@Ohio State) located in Columbus, Ohio, serves a diverse constituency of faculty, staff, and students of Ohio 
State's five health sciences colleges (which are dentistry, medicine, nursing, optometry, and public health) as well as healthcare practitioners and patients of the university's multihospital Wexner Medical Center. Over the years, HSL@Ohio State has distinguished itself for its exploration and adoption of innovative services, technologies, and unique organizational models. ${ }^{4}$ While focused primarily on the information needs of the health sciences community, HSL@Ohio State is part of a larger campus network of libraries at The Ohio State University. Ohio State enrolls more than 55,000 students across all levels of training and employs more than 40,000 faculty and staff across the campus and hospitals. The magnitude of Ohio State's research enterprise is reflected in the $\$ 983$ million of total research funding in 2014.

Authors at HSL@Emory and HSL@Ohio State applied, in tandem, common assessment and planning strategies seeking a better understanding of the information management challenges facing the community of health and biomedical researchers that each serves. Current practices and anticipated needs of researchers were examined across four categories of services and solutions: (1) information discovery and access; (2) expert information services; (3) data management services; and (4) digital capture, publishing, and preservation. Examining researcher needs across two researchintensive universities (see table 1) using a shared strategy positioned the authors to gain an understanding of the information and data management challenges facing today's researchers.

During the course of this study, an unforeseen opportunity presented itself when a coauthor departed HSL@Emory to take the position of the Executive Director of the Augustus C. Long Health Sciences Library at Columbia University Medical Center (HSL@Columbia) in New York City. This provided the authors with an opportunity to explore a hypothesis that the strategic processes and outcomes derived from examining researcher needs at Emory and Ohio State could inform planning efforts at other institutions. Sharing many characteristics with HSL@Emory and HSL@Ohio State, HSL@Columbia serves the schools of medicine, dentistry, nursing, and public health, as well as the affiliated health systems of Columbia University Medical Center and the New York Presbyterian Hospital. Detailed herein are noted outcomes by which the study's methodologies and findings were applied by a third health sciences library.

\section{Review of the Literature}

While focusing on meeting the needs of health sciences researchers, this study builds upon a growing dialogue within the broader academic library and research information communities, challenging its practitioners to rethink methods of scholarly information access and management. ${ }^{5}$ Two noteworthy reports-Research Support Libraries Group, Final Report from the United Kingdom and A Slice of Research Life: Information Support for Research in the United States commissioned by OCLC - highlight the evolving information management needs of the modern researcher in an age when digital scholarship has become the norm. These two reports examined the information resources, tools, and services used by the researchers in select academic institutions. ${ }^{6}$

As leaders in information discovery and preservation, libraries have grown accustomed to the challenges that new technologies bring. History is dotted with technological advances that have impacted libraries in interesting ways. The introduction of machine-based automation by the Ohio College Library Center (OCLC) in the late 1960s prompted libraries to refine traditional cataloging methods, while the advent of electronic library databases in the 1980s spurred the retooling of search assistance and document-delivery models. ${ }^{7}$

In the last five years, the community of academic research libraries has more aggressively examined evolving user trends, assessing the value of current service offerings. 
Emerging themes include transition of print collections to electronic resources; a more concerted push for open access; repurposing library space and staff; interinstitutional purchasing of collections; data management strategies and compliance; leading institutional efforts on the adoption of ORCIDs; and the increasing demand for embedded librarians. ${ }^{8}$ The ACRL Research and Planning Committee has noted trends in deviceneutral digital services, open and online education, competency based learning, altmetrics, and digital humanities. ${ }^{9}$

The proliferation of Web 2.0 services (such as blogs, conferencing, instant messaging, podcasts, social networking, and wikis) over the past few years has spurred many professional communities - including libraries - to explore ways of adopting these next-generation digital tools to enhance engagement, connectivity, and collaboration among academic researchers. This rush toward the next "shiny object" has motivated Gardios and colleagues to point out, however, the lack of rigorous assessment around the value and measurable outcomes of what have become known as user-centered Library 2.0 services. $^{10}$

The volume, variety, and velocity of research data bubbling up from nearly all academic disciplines prompted Ashley to challenge librarians to play a more proactive role in research data management to "ensure that data is preserved, citable, findable and reusable." Examples cited include having libraries assist researchers in identifying data sets already in existence and taking the lead on developing and managing data registries for researchers. Ashley opined that, while "libraries cannot solve these issues alone, they can catalyze institutional action on research data management strategies by bringing together those in information technology services, research computing, research administration and the researchers themselves to find institution-wide solutions." ${ }^{11}$ Such cross-organization problem solving is beginning to find its way into operational practice. At the University of Michigan, rather than looking to the historical providers of research services, librarians at the Taubman Health Science Library worked collaboratively with their colleagues in the Medical School's Office of Research to create new information management techniques to support grant preparation and submissions. ${ }^{12}$

Recognizing that developing new sustainable service models around digital scholarship is not without its challenges, Vinopal and McCormick recently described an approach and lessons they learned from work conducted at New York University Libraries. They stressed the importance of developing a library culture that is adaptable and welcomes change. ${ }^{13}$

Recent literature highlights the expanding professional development needs and responsibility changes for health sciences librarians. Health sciences librarian roles have evolved during the last decade as librarians retool their professional skills to serve as informationists, liaisons, and embedded librarians working on clinical care and research initiatives. ${ }^{14}$ McIntire recently reported that health sciences researchers are now "embedding" librarians in their research teams to more closely assist with compliance for new government funding requirements directly related to grants, data management, and open access. ${ }^{15}$ In yet another example, sequencing of the human genome in 2001 and the proliferation of DNA data that followed spurred many health sciences libraries to develop information services in molecular biology and genetics to help researchers select and use related bioinformatics tools. ${ }^{16}$ The growing availability of genomic, proteomic, and clinical data sets caused Grefsheim and colleagues to examine information-seeking patterns and unmet needs of scientists at the National Institutes of Health with an eye toward developing methods, solutions, and service improvements to help researchers navigate the oft-fragmented ways of analyzing, organizing, and managing the deluge of digital biomedical information. ${ }^{17}$ 
While health science librarians strive to remain attuned to the information demands of the organizations they serve, understanding the breadth and depth of resources and services needed by researchers has not always been as clearcut. Several studies have examined researcher information-seeking behaviors and preferences, but little attention has been paid to forecasting the information resources and services that researchers, specifically, will need. This study sets out to document these information services needs and help inform organizational retooling. ${ }^{18}$

\section{Methodology}

To understand the needs of biomedical researchers at Emory and Ohio State, a fifteenquestion web-based survey was developed aimed at collecting user needs across four categories of modern information services that included: (1) information discovery and access; (2) expert information services; (3) data management services; and (4) digital capture, publication, and preservation. In addition to exploring demand for the four categories of information services, participants were also asked to assess the perceived impact of these service innovations on their scholarly work and rank appropriate funding models for the service provisions.

Various departments known to offer information and technology services on both campuses were asked for input and perspective on the survey before its final launch. Additionally, the survey was validated for vocabulary clarity and succinctness with these collaborators and a sample of library customers. Once finalized, the survey was packaged as a joint submission to Institutional Review Boards at both institutions, where it secured exemption status by each board. (For the survey instrument, see appendix 1.)

E-mail distribution lists were then compiled for each institution accounting for nuanced differences between the two schools (see table 1). For the Ohio State population, a list of 3,000 randomly generated e-mail addresses, from all university colleges and schools, was obtained from the university's Office of Research containing faculty of all ranks and types, staff members, and graduate students, whose job titles reflected research-related functions (that is, postdoctoral fellow, research associate, research assistant, graduate research assistant, and others). A list of 3,500 e-mail addresses was obtained for all biomedical and health sciences researchers served by HSL@Emory. An e-mail communication-customized for each campuswas then distributed widely across each campus announcing the upcoming study, its purpose, and context. Following this general announcement, e-mail invitations were sent to the randomly selected researchers at Emory and Ohio State soliciting their participation in the survey. To minimize cross-contamination of respondent data, the final survey was set up in duplicate form using SurveyMonkey, directing invitees at Emory and Ohio State to separate and unique URL addresses. The tandem surveys were distributed in 2012. The surveys were posted for two weeks, with one reminder communication.

Five general demographic questions were asked of each respondent to enable proper data analysis while preserving anonymity. These research-focused demographic questions queried each participant to specify his or her role, discipline, home college, external funding status, and number of active years in research. Responses were completely anonymous; no personal information (such as user identifiers, organizational identifiers, Internet Protocol addresses, or time stamps) was collected that could be used to identify participants. Analysis focused on each institution, both separately and together, exploring overall frequencies and other descriptive statistics by question. Where appropriate, results were further delineated by researcher role and discipline. 


\section{Results}

\section{Demographics of Study Participants}

Despite institutional differences, the response patterns of faculty, research staff, postdoctoral fellows, and graduate students invited to participate from the biomedical and health sciences were strikingly similar, albeit somewhat modest in number. Response rate for these disciplines included 160 respondents from Emory (5\%) and 189 respondents from Ohio State $(6.3 \%)$ respectively.

Participants from both institutions indicated overall satisfaction with the quality of information services they receive from their local library and information technology organizations, with 100 (72\%) of Emory and 151 (80\%) Ohio State participants agreeing or strongly agreeing with the assertion that they were satisfied with the level of service received.

Those who completed the survey at Emory were nearly evenly distributed across the decade ranges of $1-10$ years (34.3\%), $11-20$ years (33.5\%), or $21+$ years $(32.1 \%)$ when asked to indicate the total number of years they have been actively involved in academic research. Nearly three quarters of the Emory respondents indicated faculty rank status

\begin{tabular}{|c|c|c|c|}
\hline \multicolumn{4}{|c|}{$\begin{array}{c}\text { TABLE } 1 \\
\text { Institutional Attributes }\end{array}$} \\
\hline & & Emory University & The Ohio State University \\
\hline \multirow{5}{*}{ 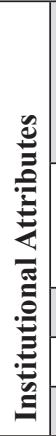 } & Carnegie Classification & $\begin{array}{c}\text { RU/VH : } \\
\text { Research Universities } \\
\text { (Very High Research } \\
\text { Activity) }\end{array}$ & $\begin{array}{c}\text { RU/VH : } \\
\text { Research Universities } \\
\text { (Very High Research } \\
\text { Activity) }\end{array}$ \\
\hline & Size And Setting & $\begin{array}{c}\text { L4/HR: } \\
\text { Large Four-Year, Highly } \\
\text { Residential }\end{array}$ & $\begin{array}{c}\text { L4/NR: } \\
\text { Large Four-Year, Primarily } \\
\text { Nonresidential }\end{array}$ \\
\hline & Faculty And Staff Count & 28,000 & 25,000 \\
\hline & Student Count & 12,930 & 55,000 \\
\hline & External Grants (FY13) & $\$ 501 \mathrm{M}$ & $\$ 934 \mathrm{M}$ \\
\hline \multirow{9}{*}{ 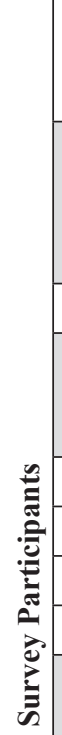 } & $\begin{array}{l}\text { Targeted Research } \\
\text { Professions }\end{array}$ & $\begin{array}{l}\text { Graduate Students, } \\
\text { Postdoctoral Fellows } \\
\text { Faculty }\end{array}$ & $\begin{array}{l}\text { Graduate Students } \\
\text { Postdoctoral Fellows } \\
\text { Faculty }\end{array}$ \\
\hline & $\begin{array}{l}\text { Targeted Research } \\
\text { Disciplines }\end{array}$ & $\begin{array}{l}\text { Biomedical and Health } \\
\text { Sciences ONLY }\end{array}$ & $\begin{array}{c}\text { All Colleges and } \\
\text { Departments with a Close } \\
\text { Look at Biomedical and } \\
\text { Health Sciences }\end{array}$ \\
\hline & Invitations Sent & 3500 & 3000 \\
\hline & $\begin{array}{l}\text { Response Rate } \\
\text { (Biomedical \& Health } \\
\text { Sciences Cohort) }\end{array}$ & $160(5 \%)$ & $189(6 \%)$ \\
\hline & Researcher Experience & & \\
\hline & $0-10$ Years & $48(34 \%)$ & $118(62 \%)$ \\
\hline & $11-20$ Years & $47(33 \%)$ & $34(18 \%)$ \\
\hline & $21+$ Years & $45(32 \%)$ & $37(20 \%)$ \\
\hline & $\begin{array}{l}\text { Currently Receiving } \\
\text { External Funding }\end{array}$ & $102(73 \%)$ & $165(87 \%)$ \\
\hline
\end{tabular}


and currently receiving external research funding. Participants from Ohio State were generally younger researchers, with $118(62 \%)$ reported having ten or fewer years of experience in academic research and scholarship. One hundred sixty-five (87\%) Ohio State researchers indicated their research was presently funded (see table 1). Of note is that the distribution from both institutions of those who opted to participate in the voluntary study was representative of overall institutional demographics.

\section{Bringing Value to Scholarship}

Presented with a list of twenty-two information service offerings mapped across the four broad categories of: (1) information discovery and access; (2) expert information services; (3) data management services; and (4) digital capture, publication, and preservation, researchers were asked to indicate the overall value that each could bring to their scholarly efforts. As detailed in figure 1, the findings showed similar patterns among the researchers at both institutions.

Of the twenty-two services, those ranked by biomedical researchers as the ones that could bring the most significant value to their work included: (1) improved searching across federated sources; (2) access to secure, shared data storage; and (3) enhanced

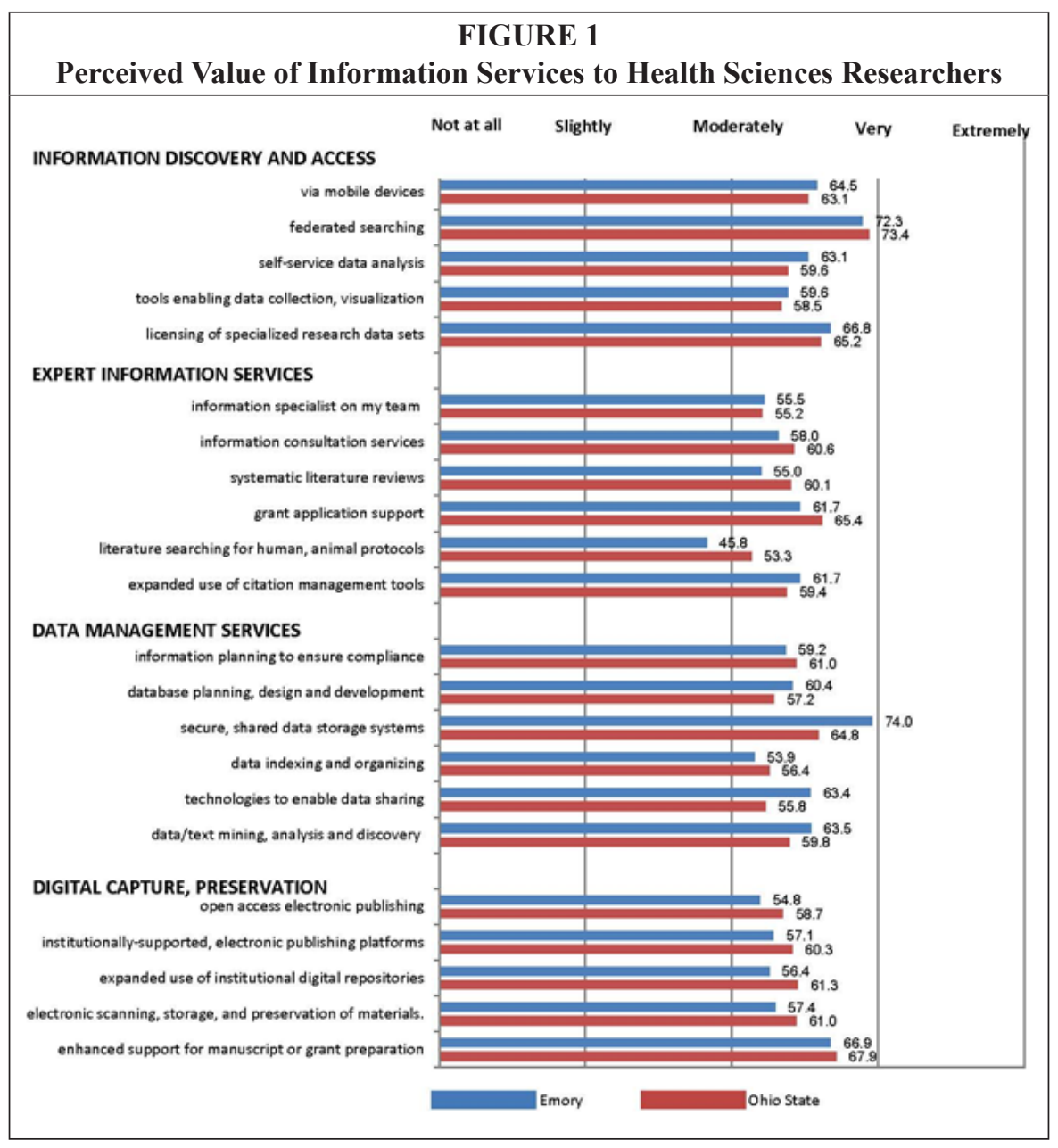


support for manuscript or grant preparation. Those services ranked of least value included data indexing and literature searching for human and animal protocols.

Many parallels were found when comparing value rankings of specific services in each of the four general categories. Among those mapping to information discovery and access, integrated searching across multiple collections (72.3 Emory, 73.4 Ohio State) and coordinated licensing/purchasing of specialized research data sets (66.8 Emory, 65.2 Ohio State) ranked among the highest need. The lowest ranked services in this category included enhanced institutional support for the development of custom web and mobile-computing applications to enable data collection or visualization (59.6 at Emory, 58.5 at Ohio State).

When considering the services listed in the category of Expert Information Services, demand for scientific publication and grant application editing and consultation (61.7 Emory, 65.4 Ohio State) ranked among the highest at both schools, with literature searching for human and animal protocols (45.8 Emory, 53.3 Ohio State) ranking the lowest.

Among the services included in data management services, provisioning reliable and secure shared data storage (74 Emory, 64.8 Ohio State) ranked near the top of researcher demands. These numbers were reinforced by the open comments captured in both surveys where participants stressed the need for centralized and accessible data storage solutions. Services generating less interest in this category were institutionally specific and included data indexing and organizing (53.9, Emory) and grid-enabled networking and technologies for sharing data sets (55.8, Ohio State).

Finally, service offerings categorized as digital capture, publishing, and preservation showed a high demand for enhanced support for manuscript and grant preparation (66.9 Emory, 67.9 Ohio State), while promoting awareness and support for open access publishing and scholarly works was ranked lowest (54.8 Emory, 58.7 Ohio State) in this category.

\section{Funding Models and Ranking of Impact}

Funding new information service offerings is an important consideration and often serves as a key delimiter for organizations. When queried about funding models to develop and sustain any of these information services, participants at both institutions, not surprisingly, preferred that institutional funding underwrite the cost of doing business. However, digital capture, publishing, and preservation was the one service category where participants at both schools seemed comfortable with a fee-for-service model. Narrative captured in the open comments spoke specifically to a general willingness of participating researchers to pay for digitization services.

Faced with flat-or worse, declining - budgets, organizations must explore creative ways to underwrite the costs of new service offerings. What underused or obsolete services can be targeted for sunsetting? What revenue-sharing partnerships can be fostered? Which new service might have a greater impact on scholarship, researcher, or institutional outcomes? In search of such insights, participants at Emory and Ohio State were asked to rank the four categories of service innovations and the relative impact they could have on their research activities. The resulting preference data revealed similar patterns of distribution. As detailed in figure 2, investigators at both schools noted that service innovations mapping to expert information services (such as comprehensive searching, scientific writing and grant preparation, embedded information support, and assessing scholarly outcomes) were most likely to have the greatest impact on their research. Scanning and storage of digital materials and support of electronic publishing platforms among other digital capture, publishing, and preservation services were predicted to have the least long-term impact on their scholarship. 


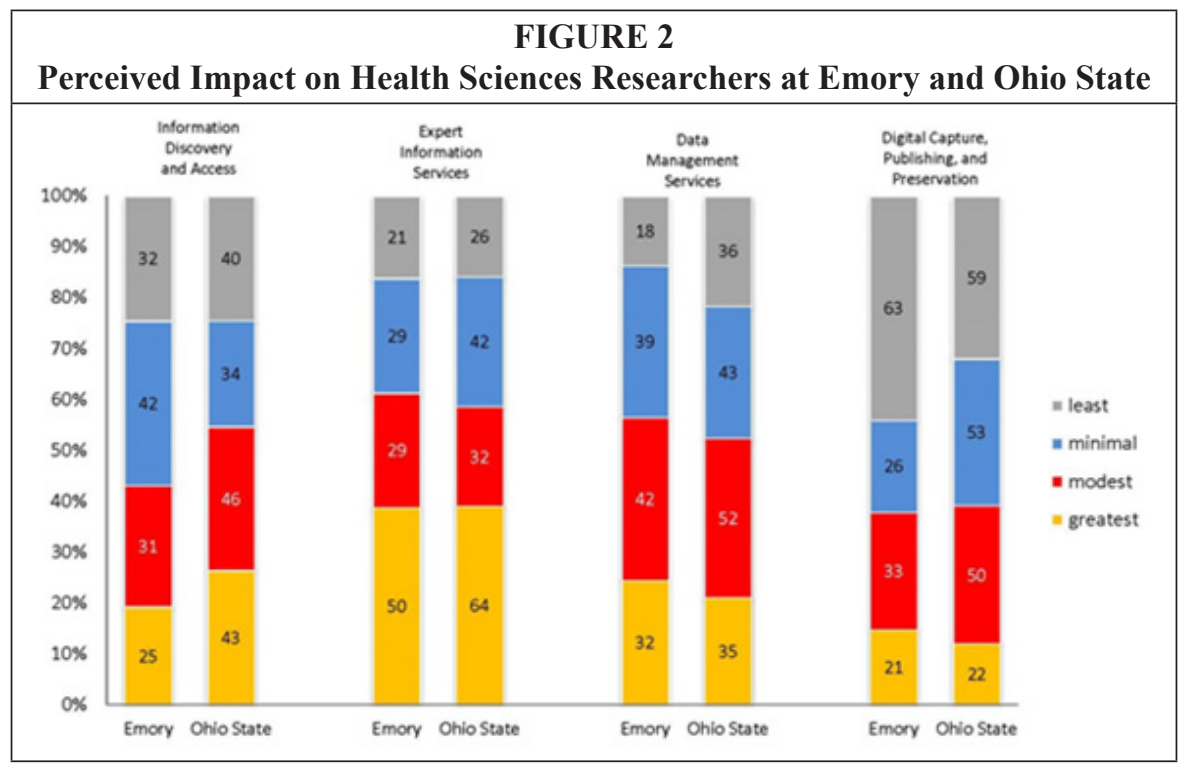

\section{A Glimpse beyond the Health Sciences}

The demands for relevant and cutting-edge information services in academic medical centers have long challenged health sciences libraries to anticipate, pilot, and operate new service models that are often more broadly adopted. So while this cross-institutional survey examined primarily the information needs of health sciences researchers, authors at Ohio State had the opportunity to extend its assessment of scholarly needs across the broader range of disciplines. A total of 437 researchers at OSU participated, providing a 15 percent response rate overall.

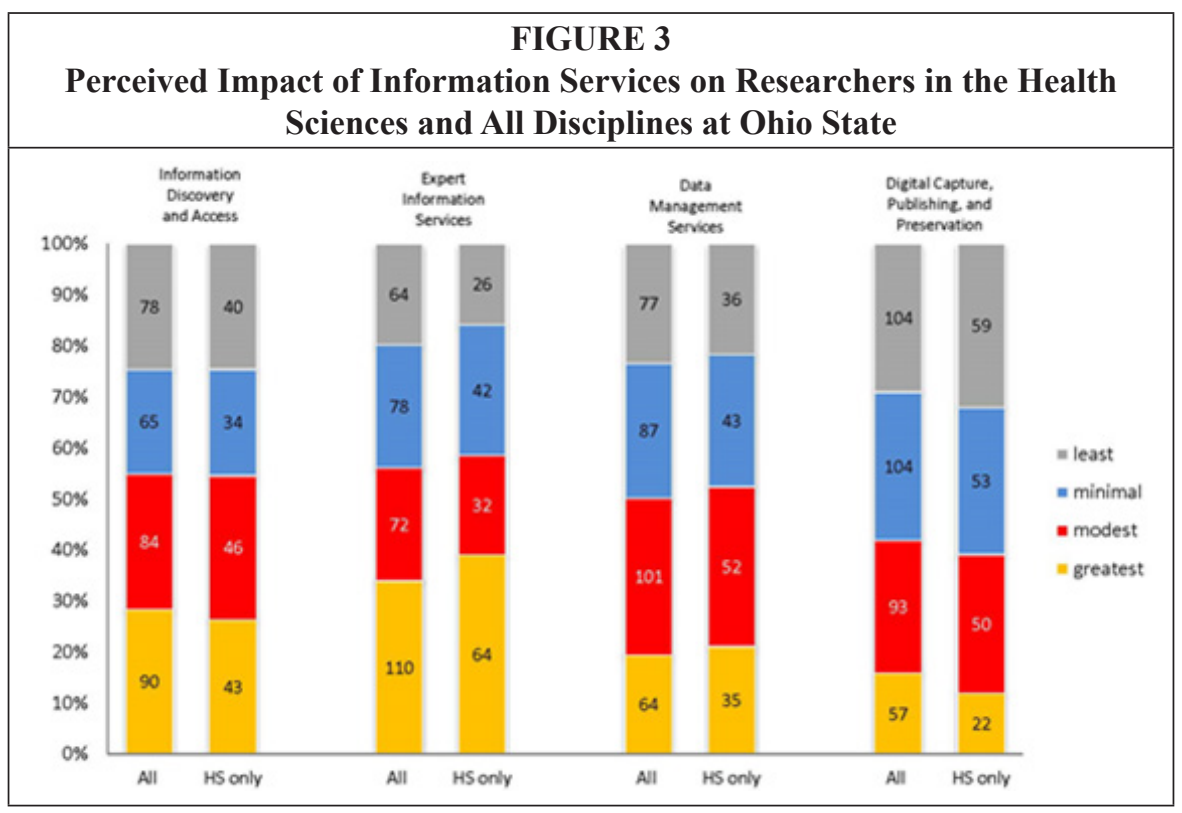


It is noteworthy that $285(82 \%)$ participants from Ohio State indicated an appreciable level of satisfaction with the quality of the information services available institutionally to support their scholarship activities. This satisfaction level was only slightly higher $(2 \%)$ than that of the biomedical and health sciences audience. Expert information services ranked among the offerings that could have the most significant impact on the participants' research activities $(56 \%)$, where specific services of interest included scientific and grant application editing and publication consultation (57\%) and systematic literature review searching and consultation (51\%). Information discovery and access ranked closely behind (54\%), with participants noting the need for enhanced integrated searching across campus (73\%) and coordinated licensing/purchasing of specialized research data sets (49\%). Digital capture, publishing, and preservation was a category of service offerings that both the biomedical and broader research communities at Ohio State indicated would have the least impact on their academic scholarship. (The impact rankings of each service category are detailed in figure 3.)

\section{Discussion}

The results of this study offer meaningful insights into the needs of research-active faculty, staff, and graduate students in the health and biomedical sciences and have already provided valuable justification for new or expanded information services at Emory, Ohio State, and Columbia. Preliminary findings of this study were presented in May 2013 at the Annual Meeting of the Medical Library Association. ${ }^{19}$

\section{Lessons Applied at Emory}

Following the completion of the survey and its analysis, the results were presented to Emory's Research Advisory Committee, who responded favorably to its usefulness in planning for future services at Emory. The HSL@Emory used the insights gleaned to develop new services and to adjust current service offerings to better meet the needs uncovered.

One service that surfaced among the Emory researchers, postdocs, and graduate students was the need for grantwriting support. With this information in hand, print and electronic resources on grant, fellowship, and scientific writing were added to the HSL@Emory collection and a new "Writing and Publishing" section added to its redesigned website. Concerted energy focused on raising awareness of existing services, such as reference management assistance, research impact assessment, copyright management, and NIH public access compliance.

Observing the institutional demand for additional data management services and access to secure shared data storage solutions prompted a joint information technologies and libraries working group to push forward the Emory-wide adoption of the Box. net, a cloud-based solution to provide faculty, staff, and students with 25 Gigabytes of digital document storage and to help fuel greater interdisciplinary work among internal and external collaborations.

Influenced by the findings, HSL@Emory created and hired a Research Informationist, using the insights gleaned to plan the types of information services offered by the position. The impact of this new position was soon recognized when approached to offer graduate-level instruction in the use of genomic analytical tools, resources, and methodologies, such as those made available through the National Center for Biotechnology Information. The HSL@Emory licensed a suite of genomics and structural biology software (such as Lasergene) for the research labs and expanded its genomic software offerings (for example: MetaCore, NextBio, BioBase, and Open Helix tutorials).

Soon thereafter, HSL@Emory planned the recruitment of a second Informationist to support the growing needs of the Rollins School of Public Health at Emory, with many 
of the supported services informed by the user-based evidence. The Public Health Informationist created the HSL@Emory Data Blog (see http://whscldatablog.wordpress. $\mathrm{com} /$ / highlighting data sets, tools, and analytical software of interest and set up a specialized software lab (see http://health.library.emory.edu/biomedical-resources/ software/specialized-software.html), containing computers loaded with institutionally licensed and publicly available statistical analysis software (examples being SPSS, SAS, R, MATLAB, and STATA) and several geospatial analysis software packages.

\section{Lessons Applied at Ohio State}

Survey findings in hand, the Ohio State authors circled back with survey design collaborators, campus librarians, and the Administrative Research Council-a campus organization with research-focused employees from all colleges and centers.

The need for additional grant and manuscript writing and editing remains a theme that echoes throughout the research community including the University Office of Research, the Life Sciences Network and various departments on campus. Following the survey, HSL@Ohio State librarians began investigating writing services available on campus, before setting up and contracting with an external scientific writing company to offer discounted editing services to Ohio State faculty and staff; HSL@Ohio State continues to explore options for expanding editing services on campus.

Researcher training and workshops have grown as a result of the survey. New programs have included a panel discussion of journal editors sharing strategies for manuscript submission and successful acceptance, workshops for researchers and support staff regarding NIH Public Access Policy tools and policy compliance, programs regarding the selection and use of citation management tools, and additional sessions covering copyright law and authors' rights. As other federal government agencies begin to follow the lead of NIH mandating public access to data sets, publications, and other scholarly outcomes to sponsored project funding, librarians are preparing to offer expanded compliance support.

In the study, Ohio State researchers articulated the need for coordinated licensing of specialty genetic databases; HSL@Ohio State responded by engaging university purchasing officials to identify opportunities for economies of scale and coordinated procurement, before facilitating contact with appropriate database vendors to explore cost-sharing opportunities.

Data storage and management assistance was another highly ranked service item uncovered in the Ohio State survey results. HSL@Ohio State librarians have started staff retooling efforts through professional development programs, collaborating with data management librarians across campus, to begin providing expert assistance with data management plans, a growing expectation of grant applications.

Ohio State sponsors an annual Research Expo targeted for new faculty and staff across campus, which HSL@Ohio State has actively exhibited over the years. Being armed with the study results has helped HSL@Ohio State to prioritize the information services and tools emphasized and promoted. Attendance at this annual event has helped librarians form new relationships with various groups in the campus research community, and new researchers are introduced to the wide range of library information services available to them.

HSL@Ohio State librarians have developed a subject guide for researchers to steer them through the myriad set of university research systems, resources, and requirements, noting library services throughout. The guide details the research life cycle and provides researchers with a roadmap through the circuitous processes and steps they will likely encounter and targets ways to engage library information services to help achieve their professional goals. 
Finally, one of the most exciting new library programs to be developed and influenced by the present study is a new Research Commons established by university libraries, an actual and virtual hub designed to provide researchers with the services and solutions they have been asking for. Librarians from HSL@Ohio State, their campus peers, and other partners have begun collaborating in workshops and programs targeted especially to graduate students, faculty, and research staff.

\section{Lessons Applied at Columbia University Medical Center}

As noted earlier, when one of the authors accepted the directorship at HSL@Columbia, an opportunity presented itself to examine the utility of this evidence-based approach to planning and apply its findings and efforts at yet another institution. Access to the study findings from HSL@Emory and HSL@Ohio State prompted library administration and staff at HSL@Columbia to rethink its approach to an assessment of user needs. The responses, from the clinical and research faculty at Emory and Ohio State, made it apparent that understanding how faculty engages with data, information, and knowledge in real time is key to optimal information service composition on any biomedical campus. Additionally, the findings and insights culled from the EmoryOhio State study influenced two new initiatives at HSL@Columbia.

The first initiative was to develop a systematic, integrated approach to monitoring and analyzing behaviors and activities relative to all aspects of information and data engagement at HSL@Columbia. A new User Experience Strategist position was created focused on developing a consistent, systematic, and cross-functional approach for this initiative. The overarching strategic goal for the library and for this position was to develop a roadmap to drive near and long-term improvements and help drive a transformation in how the Columbia University Medical Center (CUMC) community engages with data and information. Based on the implications from survey findings, it became imperative for the library to build an extensive and consistent set of user experience analytics to guide future information service developments. HSL@Columbia began exploring the adoption of solutions (such as Desktracker and KnowledgeTracker) to collect and analyze data resulting from user-related transactional activities; they continue to investigate the use of embedded analytics to generate ongoing tracking of user experiences outside the traditional transactional model. Additionally, an Electronic Resources Librarian position was transformed into a Knowledge Management Strategist responsible for developing methodologies for monitoring data outcomes from the use and production of scholarly output at CUMC. While all these developments are in early stages, the discussions around data streams and some early analyses of small data sets enable library staff to better understand the underlying drivers and forces of change in the current information environment, better respond to immediate needs, and think strategically of possibilities for future engagement with the user community at CUMC.

The second initiative influenced by the study was the HSL@Columbia effort to build a portfolio of programs that create a scalable, streamlined set of service offerings throughout the CUMC campus and extend the utility and effectiveness of information resources and services. Within this initiative, a new Programs Director position was created to oversee planning, directing, and implementation of library initiatives and programs, prioritizing library projects based on feasibility, use of resources, and institutional impact. Already, the library began a new Systematic Reviews Advisory program, focusing on unbundling offerings within this program as a set of options. What is new for the library is the effort to describe services with a focus on outcomes, metrics, and mechanics of measuring service effectiveness as a way to be transparent with the users and administration. 
In effect, the survey provided HSL@Columbia with a theoretical foundation and environmental scan that allowed it to move forward with the two strategic initiatives much faster than it would have done otherwise. It provided the HSL@Columbia with the necessary understanding of new and increasingly complex issues facing both the users and information professionals on academic campuses in a way that prompted meaningful discussions within the library staff, as well as administrators and faculty.

\section{Study Limitations}

Due to the survey process, the authors of this study were limited to volunteer-reported data, bringing with it the potential for respondent bias. Because the surveys were distributed by library and research leadership, participants may have felt inclined to rank higher those services believed to be offered or managed by these groups.

The total response rate of 15 percent included all disciplines at Ohio State and was identified by statistical office staff as reasonable, given the distribution size. The rate of response by health and biomedical sciences researchers at both campuses was smaller. Due to a variety of circumstances, the authors ended up distributing the surveys over a winter holiday break. Even with one reminder, the distribution timing may have hampered the result rates.

It is possible that the complex nature of some of the topics may have contributed to lower response rates. Another concern about the survey is the grouping of services. There are some service groupings that could have been separated to clarify specific preferences and impact. For example, literature searching services could have been separated from data management planning in the expert information services category.

\section{Conclusion}

The information needs of health and biomedical researchers are complex and continuously changing. Academic scholars are looking for convenient, efficient, and timely services that will enable them to successfully compete for grants, publish their study outcomes, and access, store, and share their data easily and securely. Advances in information management technologies supporting the academic research enterprise require the joint expertise and creativity of librarians, information technology professionals, and research administrators.

Many studies have demonstrated that librarians and other information professionals are working diligently to explore and assess new roles and responsibilities to meet the information management needs of academic researchers. ${ }^{20}$ The strikingly similar results and program needs identified by the Emory and Ohio State survey participants across the health and biomedical research community serve as an additional call to action for expanding the roles of librarians and the services they provide.

As detailed herein, the environmental pressures faced by health sciences libraries to respond with relevant, timely, and well-tooled services can be daunting. Health sciences libraries have worked long and diligently to monitor user, resource, and workflow trends being driven to respond by retooling and operationalizing new service models when warranted. While this study focused primarily on exploring current and future needs of researchers across the health and biomedical professions, it can be reasonably argued that the strategies applied, findings observed, and insights gleaned from examining information and user patterns among health sciences researchers can help forecast trends to follow across the broader community of academic libraries.

This study and resulting program developments at Emory, Ohio State, and Columbia Universities illustrate how evidence-based librarianship can be employed, as libraries develop customer-centered information service solutions. The findings point to opportunities for additional research and collaborative program development and evaluation. 


\section{Notes}

1. Kevin Ashley, "Research Data and Libraries: Who Does What," Insights: The UKSG Journal 25, no. 2 (2012):55-57; Jayshree Mamtora, "Transforming Library Research Services: Towards a Collaborative Partnership," Library Management 34, no. 2 (2013) 352-71; Mark Minie et al., "The University of Washington Health Sciences Library Biocommons: An Evolving Northwest Biomedical Research Information Support Infrastructure," Journal of the Medical Library Association: JMLA 94, no. 3 (2006):321-29; James G. Neal, "Opportunities for Systematic Change in the Academic Research Library: Elements of the Post-Digital Library," Insights: The UKSG Journal 25, no. 1 (2012):92-97; Carla J. Stoffle and Cheryl Cuillier, "From Surviving to Thriving," Part of Special Issue Climbing Out of the Box: Repackaging Libraries for Survival 51, no. 1 (2011):130-54; Carol Tenopir, Ben Birch, and Suzie Allard, "Academic Libraries and Research Data Services: Current Practices and Plans for the Future" (Chicago, Ill.: Association of College \& Research Libraries, 2012).

2. Arthur Bienenstock, Ann M. Arvin, and David Korn, "Have Universities Overbuilt Biomedical Research Facilities?" Issues in Science and Technology 31, no. 3 (2015): 35-36.

3. Estelle Broadman, “Users of Health Sciences Libraries," Library Trends 23 (1974): 63-72; Gary Freiburger and Sandra Kramer, "Embedded Librarians: One Library's Model for Decentralized Service," Journal of the Medical Library Association:JMLA 9, no. 2 (2009): 139-42; Eugene Garfield, "The Impact of Hospital Libraries on the Quality and Cost of Health-Care Delivery," Current Contents, no. 8 (1983): 5-10; Bette Greenberg et al., "Evaluation of a Clinical Medical Librarian Program at the Yale Medical Library," Bulletin of the Medical Library Association 66, no. 3 (1978): 319-26; William Hersh, "Who Are the Informaticians? What We Know and Should Know," Journal of the American Medical Informatics Association: JAMIA 13, no. 2 (Mar.-Apr. 2006): 166-70.

4. "The Ohio State University Health Sciences Library and Center for Knowledge Management Honored by AAHSL with Inaugural Innovation Award . Association of Academic Health Sciences Libraries," available online at www.aahsl.org/index.php?option=com_content\&view=article\&id=14 [accessed 14 September 2014]; Timothy J. Cain et al., "Managing Knowledge and Technology to Foster Innovation at the Ohio State University Medical Center," Academic Medicine 80, no. 11 (2005): 1026-31; Barbara Ann Van Brimmer and Elizabeth J. Sawyers, "The Randtriever: Its Use at the Ohio State University," Library Hi Tech 8, no. 3 (1990):71-81.

5. Research Support Libraries Group: Final Report (United Kingdom:Higher Education Funding Council for England, 2003).; Cain et al., "Managing Knowledge and Technology," 1026-36; Van Brimmer and Sawyers, "The Randtriever," 71-81.

6. Susan Kroll and Rick Forsman, "Slice of Research Life Report [OCLC]," (Dublin, Ohio: OCLC Research, 2010); Research Support Libraries Group: Final Report, 2003.

7. C.W.J. Bailey, "The University of Houston Libraries' Chemistry Research Information Service. A Research Support Service Based on End-Use Searching and Document Delivery," Report No: ED 305078 (1988); Sheila S. Intner, "The Passing of an Era," Technicalities 27, no. 2 (2007): 1-14.

8. David Attis and Colin Koproske, "Thirty Trends Shaping the Future of Academic Libraries," Learned Publishing 26, no. 1 (2013): 18-23.

9. “2012 Top Ten Trends in Academic Libraries," College E Research Libraries News 73, no. 6 (2012): 311-20.

10. Paulo Gardois et al., "Implementation of Web 2.0 Services in Academic, Medical and Research Libraries: A Scoping Review," Health Information Libraries Journal 29, no. 2 (2012): 90-109.

11 Ashley, "Research Data and Libraries: Who Does What," 352-71.

12. Christine Black et al., "Collaboration between the University of Michigan Taubman Health Sciences Library and the University of Michigan Medical School Office of Research," Medical Reference Services Quarterly 32, no. 2 (2013): 179-84.

13. Jennifer Vinopal and Monica McCormick, "Supporting Digital Scholarship in Research Libraries: Scalability and Sustainability," Journal of Library Administration 53, no. 1 (2013):27-42.

14. Jane Blumenthal, "Creating the Future," Journal of the Medical Library Association: JMLA 102, no. 1 (2014): 2-4.

15. Mary Ellen McIntire, "Librarians Leap to the Aid of Researchers Whose Funding Will Soon Depend on Open Access," Chronicle of Higher Education (July 30, 2015).

16. Ansuman Chattopadhyay et al., "Design and Implementation of a Library-Based Information Service in Molecular Biology and Genetics at the University of Pittsburgh," Journal of the Medical Library Association: JMLA 94, no. 3 (2006): 307-13; Minie et al., "The University of Washington Health Sciences Library Biocommons," 321-29.

17. Suzanne F. Grefsheim and Jocelyn A. Rankin, "Information Needs and Information Seeking in a Biomedical Research Setting: A Study of Scientists and Science Administrators," Journal of the Medical Library Association: JMLA 95, no. 4 (2007): 426-34. 
18. Grefsheim and Rankin, "Information Needs and Information Seeking in a Biomedical Research Setting," 426-34; Laura L. Haines et al., "Information-Seeking Behavior of Basic Science Researchers: Implications for Library Services," Journal of the Medical Library Association: JMLA 98, no. 1 (2010): 73-81.

19. Fern M. Cheek et al., "Mapping Expressed Information Needs and Preferences of Modern Academic Researchers to Information Services and Technologies," paper presented at One HEALTH: Information in an Interdependent World: Joint Annual Meeting and Exhibition of the Medical Library Association, the 11th International Congress on Medical Librarianship, the 7th International Conference of Animal Health Information Specialists, and the 6th International Clinical Librarian Conference: Boston, Mass. (2013).

20. Janet A. Crum and I. Diane Cooper, "Emerging Roles for Biomedical Librarians: A Survey of Current Practice, Challenges, and Changes," Journal of the Medical Library Association: JMLA 101, no. 4 (2013): 278-86; Janice Jaguszewski and Karen Williams, New Roles for New Times: Transforming Liaison Roles in Research Libraries (Washington, D. C.: Association of Research Libraries, 2013); Katherine T.L. Vaughan et al., "Development of the Research Lifecycle Model for Library Services," Journal of the Medical Library Association: JMLA 101, no. 4 (2013): 310-14.

\section{Appendix 1. Survey}

Welcome! To better understand how digital advances are reshaping the design, practice, and outcomes of academic research and scholarship at Ohio State University (or Emory University), we are conducting a short survey and invite your participation.

Focusing on information services and resources needed to advance research, you are invited to voluntarily participate in this 15-question survey.

This study has been reviewed and designated exempt from IRB review by the Office of Responsible Research Practices at The Ohio State University (or Emory University).

Thank you in advance for your time.

\section{Indicate how valuable each of the following information service innovations could be to your research and scholarly activities.}

INFORMATION DISCOVERY AND ACCESS

Not at All | Slightly | Moderately | Very | Extremely

A. Access to library and other university information resources via mobile devices (such as iPods, Blackberries, other smartphones, tablets)

B. Integrated (Google-like) searching across multiple campus-based collections of information and multimedia (like images, video, files)

C. Access and support for computer-based tools that enable self- service data and information retrieval, manipulation, visualization, and analysis (examples: genomic analyzers, astronomy tools, natural language processing)

D. Enhanced institutional support for development of custom web and mobile computing applications to enable data collection or visualization of findings

E. Coordinated licensing/purchasing of specialized research datasets, databases (for instance, clinical studies, epidemiological, genomic, geosciences)

\section{Indicate how valuable each of the following information service innovations could be to your research and scholarly activities.}

EXPERT INFORMATION SERVICES

Not at All | Slightly | Moderately | Very | Extremely 
A. Integrating an information specialist into my research team to perform literature searching, data planning, information analysis, and other workflow activities.

B. Consulting/advisory services provided by information specialist (such as oneon-one custom searching or data analysis)

C. Systematic literature review searching and consultation

D. Scientific and grant application editing and publication consultation

E. Literature searching assistance for human and animal protocols

F. Advanced training on the use of citation management tools to assess scholarly outcomes and research impact (examples: RefWorks, EndNote, ISI Web of Science)

3. Indicate how valuable each of the following information service innovations could be to your research and scholarly activities.

DATA MANAGEMENT SERVICES

Not at All | Slightly | Moderately | Very | Extremely

A. Information planning support to ensure compliance with NIH, NSF, et al. standards and requirements for data sharing

B. Database planning, design, and development

C. Access to reliable and secure shared data storage systems

D. Data indexing and organizing, using keywords to optimize discovery, sharing and reuse (examples: metadata, taxonomies, ontologies)

E. Grid-enabled networking and system technologies to enable researchers to share datasets with intra- and extramural collaborators securely and easily

F. Training, tools, and expert support of data/text mining, analysis and discovery (such as using analytical software, exploring data through visualization, or using national data repositories)

4. Indicate how valuable each of the following information service innovations could be to your research and scholarly activities.

DIGITAL CAPTURE, PUBLISHING, AND PRESERVATION

Not at All | Slightly | Moderately | Very | Extremely

A. Promoting awareness and support for open access electronic publishing of scholarly works (like BioMed Central, PLoS, or Hindawi)

B. Access to institutionally supported, electronic publishing platforms to enhance communication, collaborations, and outreach (such as Open Journal Systems, WordPress, or Wikis)

C. Expanded use/support of institutional digital repositories providing access to searchable collections of images, media, student works, historical collections, and the like

D. Provide electronic scanning, storage, and preservation of materials

E. Enhanced support for manuscript or grant preparation (such as writing and editing services, annotated bibliography preparation, or statistical analysis/ validation of study results)

5. Rank in order from greatest to least the relative impact that each of the aforementioned service innovation categories could have on your research. 
1 = greatest impact

$4=$ lesser impact

1. Information Discovery and Access

(examples: cross-collection searching, just-in-time access via mobile devices, data visualization, coordinated licensing of specialized research datasets)

\section{Expert Information Services}

(examples: comprehensive searching, scientific writing and grant preparation, embedded information support, assessing scholarly outcomes)

\section{Data Management Services}

(examples: database planning, shared storage, metadata use, enhanced data sharing, data mining, digital preservation)

4. Digital Capture, Publishing, and Preservation

(examples: scanning and storage of digital materials, electronic publishing platforms, OpenAccess publishing, digital repositories)

6. In your opinion, which of the following funding approaches seems reasonable as a means to develop and sustain the research service innovations?

\section{KEY}

$A=$ institutionally funded as a core service

$\mathrm{B}=$ considerable institutional support with user fees for specialized services

$\mathrm{C}=$ mixed to balanced funding

$\mathrm{D}=$ considerable emphasis on user-based fees with institutional subsidies

$\mathrm{E}=$ user/service-based fees

$\mathrm{F}=$ not applicable

\section{Information Discovery and Access}

(examples: cross-collection searching, just-in-time access via mobile devices, data visualization, coordinated licensing of specialized research datasets)

\section{Expert Information Services}

(examples: comprehensive searching, scientific writing and grant preparation, embedded information support, assessing scholarly outcomes)n

\section{Data Management Services}

(examples: database planning, shared storage, metadata use, enhanced data sharing, data mining, digital preservation)

4. Digital Capture, Publishing, and Preservation

(examples: scanning and storage of digital materials, electronic publishing platforms, open access publishing, digital repositories)

7. How frequently do you use the following resources to stay informed about new information services that support your research?

Never | Rarely | Occasionally | Somewhat | Very Often

- $\quad$ Talking with peers and colleagues 
- Newsletters/communications

- E-mails from internal and external campus groups

- Browsing websites of interest

- $\quad$ Reading journals of interest

- Social networking resources (such as following Twitter or reading blogs)

8. How frequently do you use the following resources when actively seeking information that supports your research?

Never | Rarely | Occasionally | Somewhat | Very Often

- Visit the library

- Website of main library

- Website of health sciences library

- Web searching (via search engines like Google or Bing)

- Website of journals/publishers of interest

- Mobile accessible sites/resources

- Third-party databases, online catalogues (such as PubMed, WorldCat, or ISI)

9. Which of the following best characterizes the total number of years you have been actively involved in academic research and scholarship?

- $0-5$ years

- 6-10 years

- 11-15 years

- 16-20 years

- 21-25 years

- $26+$ years

10. Which of the following best describes your primary research role?

- $\quad$ Basic science faculty/researcher

- Clinical faculty/ researcher

- Educator/scholar

- Research staff (technician, laboratory assistant)

- Staff scientist, post doc, research fellow

- Student (undergraduate, professional, graduate)

- $\quad$ Other (please specify)

11. Please identify your primary college affiliation.

- Arts and Sciences

- Business

- Dentistry

- Education and Human Ecology

- Engineering

- Food, Agricultural, and Environmental Sciences

- Law

- Medicine

- Nursing

- Optometry

- Pharmacy 
- Public Health

- Social Work

- University Libraries

- Veterinary Medicine

- Other

- Department or Center (please specify)

12. Which of the following best characterizes your primary research discipline of interest?

- Applied Sciences (architecture, computers, engineering, information systems, and the like)

- Arts and Humanities (art, history, languages, literature, philosophy, performing visual arts, and so forth)

- Biomedical Sciences (anatomy, biochemistry, genetics, microbiology, immunology, medicine, pathology, and others)

- Health Sciences (allied health, dentistry, optometry, pharmacy, public health, nursing, veterinary medicine)

- Natural Sciences (agriculture, environmental, entomology, plant biology, and so on)

- Physical Sciences (astronomy, earth, mathematics, physics, statistics)

- Social Sciences (anthropology, economics, linguistics, psychology, geography, political, sociology)

- $\quad$ Other (please specify)

13. Are your research and scholarship activities currently receiving external funding?

- Yes

- No

- Not applicable

14. In general, I am satisfied with the level and quality of the institutional information services support I receive for my scholarship activities.

- Strongly Agree

- Agree

- Disagree

- $\quad$ Strongly Disagree

15. Please provide additional information that could help address some of your unmet needs and improve your research and scholarship activities. 